\title{
Pleistocene phylogeography and cryptic diversity of a tiger beetle, Calomera littoralis, in North-Eastern Mediterranean and Pontic regions inferred from mitochondrial COI gene sequences
}

Radomir Jaskuła, Tomasz Rewicz, Mateusz Płóciennik, Michał Grabowski

Background. Calomera littoralis is a Palearctic species, widely distributed in Europe; inhabiting predominantly its Atlantic, Mediterranean and Black Sea coastlines.

Methods. Its phylogeography on the Balkan Peninsula and on the north-western Black Sea coast was inferred using a $697 \mathrm{bp}$ long portion of the mitochondrial COI gene, amplified from 169 individuals collected on 43 localities.

Results. The results revealed two genetically divergent groups/lineages, the southern one inhabiting both the Balkan Peninsula and the Pontic Region and the northern one found exclusively in the Pontic Region. Species delimitation based on DNA barcoding gap suggested an interspecific level of divergence between these groups. Multivariate analysis of eight male and female morphometric traits detected no difference between the groups, implying they may represent cryptic species. The Bayesian timecalibrated reconstruction of phylogeny suggested that the lineages diverged ca. 2.3 Ma, in early Pleistocene.

Discussion. This result from contemporary isolation of the Pontic basin from the Mediterranean that broke the continuous strip of coastal habitats inhabited by $C$. littoralis. Demographic analyses indicated that both lineages have been in demographic and spatial expansion since ca. $0.15 \mathrm{Ma}$. It coincides with the terminal stage of MIS-6, i.e. Wartanian/Saalian glaciation, and beginning of MIS-5e, i.e. Eemian interglacial, during which, due to eustatic sea level rise, a wide connection between Mediterranean and the Pontic basin was re-established. This, along with re-appearance of coastal habitats could initiate north-east expansion of the southern lineage and its secondary contact with the northern one. Isolation of Pontic basin from Mediterranean during the Weichselian glaciation did not have probably any effect on their phylogeography. 
1 Pleistocene phylogeography and cryptic diversity of a tiger beetle, Calomera littoralis, in

2 North-Eastern Mediterranean and Pontic regions inferred from mitochondrial COI gene

3 sequences

4 Radomir Jaskuła $^{1 *}$, Tomasz Rewicz ${ }^{2}$, Mateusz Płóciennik ${ }^{1}$, Michał Grabowski ${ }^{1}$

$5{ }^{1}$ Department of Invertebrate Zoology and Hydrobiology, University of Lodz, Banacha 12/16, 90-

6237 Lodz, Poland

7 2Laboratory of Microscopic Imaging and Specialized Biological Techniques, University of Lodz,

8 Banacha 12/16, Łódź 90-237, Poland

9

10

11 Corresponding author:

12 Radomir Jaskuła ${ }^{1}$

13 Ul. Banacha 12/16, 90-237 Łódź, Poland

14 Email address: radekj@biol.uni.lodz.pl

15

16

17 


\section{Abstract}

19 Background. Calomera littoralis is a Palearctic species, widely distributed in Europe; inhabiting

20 predominantly its Atlantic, Mediterranean and Black Sea coastlines.

21 Methods. Cryptic diversity and phylogeography of the species on the Balkan Peninsula and on the

22 north-western Black Sea coast was studied using a $697 \mathrm{bp}$ long portion of the mitochondrial COI 23 gene, amplified from 169 individuals collected on 43 localities. Additionally, morphology of $C$.

24 littoralis in the studied area was analysed based on the multivariate analysis of eight male and 25 female morphometric traits.

26 Results. Our results revealed two genetically divergent groups/lineages within C. littoralis, the 27 southern one inhabiting both the Balkan Peninsula and the Pontic Region and the northern one 28 found exclusively in the Pontic Region. Species delimitation based on DNA barcoding gap 29 suggested an interspecific level of divergence between these groups. The analysis of male and 30 female morphometric traits detected no difference between the groups, implying they may 31 represent cryptic species. The Bayesian time-calibrated reconstruction of phylogeny suggested that

32 the lineages diverged ca. 2.3 Ma, in early Pleistocene.

33 Discussion. This result from contemporary isolation of the Pontic basin from the Mediterranean 34 that broke the continuous strip of coastal habitats inhabited by C. littoralis. Demographic analyses 35 indicated that both lineages have been in demographic and spatial expansion since ca. $0.15 \mathrm{Ma}$. It 36 coincides with the terminal stage of MIS-6, i.e. Wartanian/Saalian glaciation, and beginning of 37 MIS-5e, i.e. Eemian interglacial, during which, due to eustatic sea level rise, a wide connection 38 between Mediterranean and the Pontic basin was re-established. This, along with re-appearance of coastal habitats could initiate north-east expansion of the southern lineage and its secondary 
40 contact with the northern one. Isolation of Pontic basin from Mediterranean during the Weichselian

41 glaciation did not have probably any effect on their phylogeography.

42

43

44

45

\section{Introduction}

The Eastern Mediterranean including the Pontic area is recognised as one of the major biodiversity and endemism hot spots on a global scale as well as a major glacial refugium in Europe (eg. Myers et al., 2000; Kotlík, Bogutskaya \& Ekmekçi, 2004; Blondel et al., 2010). Among others, it is a consequence of complex geological history of the region that was an archipelago and united with rest of the European continent only in Neogene (Pfiffner, 2014). On the other hand, a shallow epicontinental sea, Paratethys, occupied vast areas of the continent and regressed gradually leaving relics, such as Black, Azov and Caspian Sea (Nahavandi et al., 2013). Local isostatic and eustatic changes of sea level were among superior phenomena shaping local landscapes. For example, there were at least twelve saline water intrusions from the Mediterranean Sea, and eight intrusions from the Caspian Lake to the Black Sea during the last 0.67 million years (Ma) i.e. in Pleistocene (Badertscher et al., 2011). Inevitably, they played an important role in modelling diversity and distribution patterns for numerous organisms, particularly those inhabiting coastal ecosystems both in Mediterranean and in Pontic area. However, the evidence comes mostly from aquatic, predominantly marine or brackish water, taxa (e.g. Audzijonyte, Daneliya \& Vainola, 2006; Neilson \& Stepien, 2011). There is a deficiency of studies focusing upon coastal species inhabiting terrestrial habitats in this region (Akin et al., 2010).

Tiger beetles, Cicindelidae Latreille, 1806, seem to be ideal model organisms to test such assumptions. The family, with more than 2600 species, has a worldwide distribution with exception of polar regions and some oceanic islands (Pearson \& Cassola 2005). Most species, both 
63 in larval and adult stage, prefer various types of sandy areas and are habitat specialists; often

64 inhabiting coastal areas (Pearson \& Vogler 2001). Several studies dealt with phylogeography of

65 tiger beetles in various regions of the world (eg. Vogler et al., 1993; Cardoso \& Vogler, 2005;

66 Woodcock et al., 2007), yet so far only few focused on the role of sea level oscillations in their

67 evolutionary history (Vogler \& DeSalle, 1993; Sota et al., 2011) or compared the diversity patterns

68 on both, the molecular and morphological, levels (Cardoso, Serrano \& Vogler, 2009; Tsuji et al., 69 2016).

70 The tiger beetle, Calomera littoralis Fabricius 1787, is widely distributed in Palaearctic,

71 from the Iberian Peninsula and Morocco in the west to the Middle Asia and Russian Far East in

72 the east (Putchkov \& Matalin, 2003; Serrano, 2013; Jaskuła, 2011, 2015). Generally, it is

73 recognised as euryoecious (Jaskuła, 2011, 2013, 2015). However, in Europe it occupies

74 predominantly the very narrow stretch of Atlantic, Mediterranean and Black Sea coastal habitats

75 (Cassola \& Jaskuła, 2004; Franzen, 2006; Jaskuła, 2007a-b; Jaskuła, Peśić \& Pavicević, 2005;

76 Serrano, 2013).

77 Taking into account the history of recurrent closing and reopening of the connection between

78 Mediterranean and the Black Sea in Pleistocene, we hypothesised that it should leave a signature

79 in genetic and possibly morphological polymorphism of Calomera littoralis, which is commonly

80 found around both sea basins. Thus, we aimed at (1) exploring and comparing spatial patterns of

81 molecular and morphological diversity of this species in the Mediterranean and Pontic region, (2)

82 interpreting the observed patterns in the context of local paleogeography.

84 Material and methods

85 Sample collection and identification 
86 In total, 169 imagines of Calomera littoralis were collected with entomological hand net on 43

87 sites on the Mediterranean coasts of the Balkan Peninsula, Crete and Turkey as well as on the

88 northern and western coast of the Black and Azov Seas, in the years 2009-2012 (Figure 1, Table

89 1). At a site the material was fixed in $96 \%$ ethanol for DNA preservation. Taxonomic identification

90 of the collected material followed Mandl (1981).

91 DNA extraction, amplification and sequencing

92 Following Hillis et al. (1996) the standard phenol-chloroform method was used to extract DNA

93 from all the collected individuals. Air-dried DNA pellets were eluted in $100 \mu$ of TE buffer, $\mathrm{pH}$

948.00 , stored at $4{ }^{\circ} \mathrm{C}$ until amplification, and subsequently at $-20^{\circ} \mathrm{C}$ for long-term storage.

95 Fragments of mitochondrial cytochrome oxydase subunit I gene (COI), ca. 700 bp long, were

96 amplified using the Jerry and Pat pair of primers (Simon et al., 1994). Each PCR reaction was

97 conducted in a total volume of $10 \mu \mathrm{l}$ and contained DreamTaq Master Mix (1x) Polymerase

98 (ThermoScientific), 200nM of each primer and $1 \mu \mathrm{l}$ of DNA template. The thermal regime

99 consisted of initial denaturation at $94^{\circ} \mathrm{C}$ for $2 \mathrm{~min}$, followed by 34 cycles of denaturation at $94^{\circ} \mathrm{C}$

100 for $30 \mathrm{~s}$, annealing at $44^{\circ} \mathrm{C}$ for $30 \mathrm{~s}$, and elongation at $72^{\circ} \mathrm{C}$ for $60 \mathrm{~s}$, completed by a final extension

101 at $72^{\circ} \mathrm{C}$ for $10 \mathrm{~min}$. The amplified products were visualized on $2.0 \%$ agarose gels stained with

102 MidoriGreen (Nippon Genetics) to verify the quality of the PCR reactions. Then, the PCR products

103 were chemically cleaned up of dNTPs and primer residues by adding 1U of Exonuclease I (Thermo

104 Scientific) and 2U of FastAP Alkaline Phosphatase (Thermo Scientific) per sample. The COI

105 amplicon was sequenced one way using BigDye sequencing protocol (Applied Biosystems 3730xl)

106 by Macrogen Inc., Korea.

107 Molecular data analysis 
108 First, all the obtained sequences were positively verified as Calomera DNA using

109 GenBankBLASTn searches (Altschul et al., 1990). Then they were edited and assembled with

110 ClustalW algorithm (Chenna et al., 2003) using BioEdiTC 7.2.5. The resulting alignment was

111697 bp long with no gaps, and composed of 169 COI sequences. The sequence data and trace files

112 were uploaded to BOLD and subsequently also to GenBank (accession nos KU905171-

113 KU905339).

114 Pairwise Kimura 2-parameter (K2p) distances between sequences were estimated using

115 Mega 6.2 (Tamura et al., 2013). Haplotypes were retrieved using DNASp v5 (Librado \& Rozas,

116 2009). Phylogenetic relationships between the haplotypes were visualised with phylogenetic

117 network computed using the neighbour-net algorithm and uncorrected p-distances in SplitsTree

118 ver. 4.13 .1 (Huson \& Bryant 2006).

119 To test for presence of distinct operational taxonomic units (OTUs) that may represent

120 potential cryptic species/subspecies in the sequenced pool of individuals we used the Automatic

121 Barcode Gap Discovery (ABGD) procedure (Puillandre et al., 2012). The default value of 0.001

122 was used as the minimum allowed intraspecific distance. The maximum allowed intraspecific

123 distance was set to $\mathrm{P} \max =0.03$ and 0.06 , as both threshold values have been already used in

124 literature to delimit insect species (Hebert et al., 2003; Hebert, Ratnasingham \& de Waard, 2003).

125 We applied the K2P model sequence correction, which is a standard for barcode analyses (Hebert

126 et al., 2003). We used primary partitions as a principal for group definition for they are usually

127 stable over a wider range of prior values, minimise the number of false positive (over split species)

128 and are usually close to the number of groups described by taxonomists (Puillandre et al., 2012).

129 To reveal the temporal framework for the divergence of the OTUs (potential cryptic species)

130 defined within Calomera littoralis, the time calibrated phylogeny was reconstructed in BEAST, 
131 version 1.8.1 (Drummond et al., 2012). A COI sequence of Calomera lugens aphrodisia Baudi di

132 Selve 1864 from GenBank (acc. no. KC963733) was used as an outgroup. This analysis was

133 performed on a reduced dataset, containing only the most distant haplotypes from each OTU.

134 Hasegawa-Kishino-Yano (HKY) model of evolution, selected as best-fitting to our dataset in

135 MEGA 6.2, and coalescent model were set as tree priors. The strict clock with rate 0.0115 , widely

136 used for phylogenetic studies upon insects, was applied for the analyses (Brower, 1994). Five runs

137 of 20M iterations of Markov chain Monte Carlo (MCMC) sampled each 2000 iterations were

138 performed. The runs were examined using Tracer v 1.6 and all sampled parameters achieve

139 sufficient effective sample sizes (ESS $>200)$. Tree files were combined using Log-Combiner 1.8.1

140 (Drummond et al., 2012), with removal of the non-stationary 20\% burn-in phase. The maximum

141 clade credibility tree was generated using TreeAnnotator 1.8.1 (Drummond et al., 2012).

142 To provide insight into historical demography, i.e. the temporal changes of the effective

143 population size of Calomera littoralis in the studied region, we performed Bayesian Skyline Plot

144 (BSP) analysis (Drummond et al., 2005) in BEAST, version 1.8.1 (Drummond et al., 2012).

145 Separate analysis was performed for each of the two phylogenetic lineages revealed in our study

146 (see Results). The Northern Lineage was represented by 84 individuals from 22 localities, while

147 the Southern Lineage was represented by 85 individuals from 32 localities. The HKY+I model of

148 evolution was used as the best fitting model in case of the Eastern Lineage, while TN93+I was

149 used in case of the Western Lineage. Two runs of MCMC, 20M iterations long sampled each 2000

150 iterations, were performed. In both cases the runs were examined using Tracer v 1.6 (Drummond

151 et al., 2012) and all sampled parameters achieved sufficient effective sample sizes (ESS $>200)$.

152 Two models of population expansion, demographic and spatial, were examined using

153 mismatch distribution analysis (Slatkin \& Hudson, 1991; Rogers \& Harpending, 1992) and 
154 Tajima's D neutrality test (Tajima, 1989). Analyses were performed for the COI groups, using

155 Arlequin 3.5.1.3 (Excoffier \& Lischer, 2010) with 1000 replicates.

156 Morphometric data analysis

157 To test whether variation of morphometric traits reflects presence of two genetically divergent

158 lineages (potential cryptic species), measurements of eight body parameters (Fig. 2) were taken

159 from all the 69 males and 100 females used previously for the molecular analyses: 1 - right

160 mandible length (RML), 2 - length of head (LH), 3 - width of head (WH), 4 - pronotum length

161 (PL), 5 - maximum pronotum width (MPW), 6 - elytra length (EL), 7 - maximum elytra width

162 (MEW), and 8 - total body length (TBL). The principal component analysis (PCA) was performed

163 separately for each sex (Figure 3, Table 1). To test for significance $(\mathrm{p}<0.01)$ of morphological

164 differences (separately for males and females) between the two divergent lineages one-way

165 ANOSIM Pairwise Test was performed. All the above statistical analyses were done with PRIMER

1666 software (Clarke \& Gorley, 2006).

167

168 Results

169 Molecular data

170 A total of 81 haplotypes were identified in the dataset composed of 169 individuals from 43 sites

171 from the Mediterranean and the Pontic areas (Table 1). The phylogenetic network illustrating

172 phylogenetic relationships among haplotypes (Fig.4) uncovered presence of two distinct haplotype

173 groups (phylogenetic lineages). The first group, from now on defined as southern lineage, includes

17436 haplotypes present all over the studied range including the Balkan Peninsula and the Pontic

175 area. The other group, from now on defined as northern lineage, is composed of 45 haplotypes

176 present exclusively along the north-western coast of the Black Sea. The mean K2p genetic distance 
177 between both groups of haplotypes is relatively high (0.039, SD 0.007). Both variants of the ABGD

178 analysis resulted in partitioning of the dataset into two OTUs, that may represent distinct

179 operational taxonomic units - potential cryptic species or subspecies within Calomera littoralis in

180 the studied area (Fig. 3A).

181 The Bayesian time-calibrated reconstruction of phylogeny shows that the two lineages split

182 at ca. 2Ma, i.e. in early Pleistocene (Fig. 5A). Results of the BSP analyses showing the temporal

183 changes of the effective population size suggests that both lineages experienced rapid population

184 growth that has started ca. $0.15 \mathrm{Ma}$ (Fig. 5B). In both cases, a small decline in effective population

185 size may be observed in most recent times $(<0.05 \mathrm{Ma})$. Results of the mismatch analysis show that

186 both lineages are currently in the stage of both demographic and spatial expansion (Fig 5C).

187 Interestingly, geographical distribution of both lineages shows that the spatial expansion of

188 southern lineage was efficient enough to spread eastwards into the Black Sea and colonise

189 effectively the north-western Black Sea coast. The northern lineage has spread only in the Pontic

190 region.

191 Morphometric data

192 The results of PCA and ANOSIM revealed no differences in the analysed morphometric traits

193 between the southern and the northern lineages, neither in males nor in females (Fig. 3B). In PCA

194 (Fig. 3B), a very weak gradient $(\mathrm{R}=0.03)$ could be seen in case of female body length. Females

195 from the northern lineage clade were slightly larger than those from the southern one (body length;

196 ANOSIM Pairwise Tests $\mathrm{p}=0.03$ ).

197

198 Discussion and conclusions

199 Cryptic diversity of Calomera littoralis 
200 Known as very important hotspot of biodiversity, endemicity and cryptic diversity (eg. Myers et 201 al., 2000; Kryštufek \& Reed, 2004; Huemer \& Timossi, 2014; Blondel et al., 2010; Previšić et al., 202 2014; Caković et al., 2015), the southern Europe holds also the most diverse tiger beetle fauna in 203 the entire Palearctic realm (Jaskuła, 2011). Presence of cryptic diversity was already pointed out 204 for Cicindela hybrida in the Mediterranean (Cardoso, Serrano \& Vogler, 2009) as well as for

205 several species of tiger beetles occurring in other parts of the world (Vogler \& Pearson, 1996; 206 López-López, Hudson \& Galián, 2012). Thus, existence of well-defined OTUs within Calomera 207 littoralis is not surprising in the studied area. The level of divergence, $0.04 \mathrm{~K} 2 \mathrm{p}$ distance, between 208 the northern and the southern lineage is similar as those found between species of tiger beetles in 209 other studies (eg. Cardoso \& Vogler, 2005; López-López, Abdul Aziz \& Galián, 2015).

210 Interestingly, we could not detect any conclusive morphological differences between the two

211 lineages based on the multivariate analysis of eight morphometric traits. It must be mentioned that

212 three subspecies of Calomera littoralis, described on the basis of morphology, were reported from

213 the studied area: C. l. nemoralis from all the studied Balkan countries, Crete, Moldova, western

214 Ukraine and western Turkey; C. l. conjunctaepustulata (Dokhtouroff, 1887) from the Azov Sea 215 area; C. l. winkleri (Mandl, 1934) from Crete and the coastal zone of southern Turkey (Werner, 216 1991; Putchkov \& Matalin, 2003; Avgın \& Özdikmen, 2007). However, the morphological 217 differences between the subspecies, such as body size, maculation of elytra and shape of aedeagus, 218 are poorly defined and did not allow the identification of the studies material further than to the 219 species level. Unfortunately, we had no opportunity to study the topotypical material - Provence, 220 France, is locus typicus for C. l. nemoralis, Tibet for C. l. conjunctaepustulata, and Cyprus for $C$.

221 l. winkleri. Thus, we cannot exclude a possibility that the two lineages we found in our material 222 overlap with any of the above mentioned subspecies. However, only a further taxonomic revision 
223 combining more phenotypic traits, including e.g. cuticle ultrastructure, with several, mitochondrial

224 and nuclear DNA data, could help to resolve this problem. Until such revision is done, we propose

225 to use the tentative name "Calomera littoralis complex" for populations from the studied area.

\section{Phylogeography of Calomera littoralis}

227 Occurrence of $C$. littoralis in Europe is restricted predominantly to marine shorelines with sandy

228 beaches and salt marshes as main habitats (e.g. Franzen, 2006; Jaskuła, 2011; Serrano, 2013). In

229 the eastern Mediterranean it is distributed continuously all along the Adriatic and Aegean coasts,

230 Turkish Straits and the Black Sea coastline (Cassola \& Jaskuła, 2004; Jaskuła Peśić \& Pavicević

231 2005; Franzen, 2006; Jaskuła, 2007a; Jaskuła 2007b). However, pronounced genetic structure with

232 two divergent operational taxonomic units (OTUs) implies prolonged spatial isolation in the

233 evolutionary history of this species. The observed level of divergence indicates that this isolation

234 initiated an allopatric speciation. Their present distribution i.e. sympatry in the Pontic region

235 reveals secondary contact of the already divergent lineages in this area. The Bayesian time-

236 calibrated reconstruction of phylogeny shows that split between these OTUs begun in early

237 Pleistocene. This coincides with beginning of recurrent glaciations resulting in eustatic sea level

238 changes and climate aridisation that ever since dominated the global climate and landscape/habitat

239 distribution (Fagan, 2009). In the Mediterranean and in the Pontic region such global effects

240 overlaid and strengthen the local effects of tectonic plate collision leading to Alpine orogeny, i.e.

241 local land uplift and subsidence resulting in isostatic sea level changes, salinity fluctuations from

242 freshwater to fully marine and habitat mosaicism (Stanley \& Blanpied, 1980). For example, during

243 that time the connections of Pontic basin to Mediterranean Sea was lost and regained for more than

244 a dozen times (Kerey et al., 2004; Badertscher et al., 2011). A profound impact of these events on

245 the evolution and, hence, distribution of local both aquatic (Audzijonyte, Daneliya \& Vainola, 
246 2006; Nahavandi et al., 2013) and terrestrial taxa (eg. Böhme et al., 2007; Ferchaud et al., 2012).

247 We can assume that in case of $C$. littoralis, a halophilic species bound to coastal habitats, sea

248 level fluctuations would significantly affect its distribution. The $2 \mathrm{Ma}$ divergence time for $C$.

249 littoralis OTUs derived from our data coincides with one particular disconnection of the

250 Mediterranean and Pontic basins. At that time, from ca. 2 to ca. $1.5 \mathrm{Ma}$, the Meothic Sea, one of

251 several predecessors of the Black Sea, turned into the predominantly freshwater Pontos Sea/Lake

252 (Grinevetsky et al., 2015). This surely broke the formerly continuous stretch of coastal habitats

253 connecting the two basins and thus, could be an effective barrier leading to split of C. littoralis

254 population into the allopatric southern and northern lineages. Their detailed history is impossible

255 to unravel, yet results of BSP analyses reconstructing past changes in effective population size

256 indicate that both lineages started their demographic expansions at ca. $0.15 \mathrm{Ma}$. This coincides

257 with the terminal stage of MIS-6, i.e. Wartanian/Saalian glaciation, and beginning of MIS-5e, i.e.

258 Eemian interglacial (Lisiecki \& Raymo, 2005; Marks, 2011). The latter was characterized by

259 warmer climate and sea level higher by 6-9 $\mathrm{m}$ in comparison to Holocene (Kopp et al., 2009;

260 Dutton \& Lambeck, 2012). In result, a wide connection between Mediterranean and the Pontic

261 basin was re-established and the coastal habitats extended again, enabling exchange of faunas. Due

262 to deficiency of local studies, it is hard to compare our results to evolutionary history of any other

263 terrestrial taxa in the area. However, a wealth of studies showing very similar spatiotemporal

264 scenario in animal taxa comes from the coastal regions of the Gulf of Mexico and the adjacent

265 Atlantic coast (summarised by Avise, 1992). During Pleistocene, Cuba was connected with a

266 land bridge to the Florida Peninsula what lead to divergence of populations of several terrestrial

267 and aquatic animals, including also a local tiger beetle species Cicindela dorsalis Say, 1817

268 (Vogler \& DeSalle, 1993). Interestingly enough, however according to our results both lineages 
269 are until now in the stage of demographic and spatial expansion, only the southern one has crossed

270 the present Turkish straits. This asymmetry is hard to explain. Another interesting fact is that the

271 isolation of Pontic basin from Mediterranean during the following Weichselian glaciation did not

272 have probably any effect on the demography and phylogeography of the species. Based on the

273 mitochondrial DNA marker only we cannot also conclude, whether the secondary contact of the

274 divergent lineages effected in hybridization and or introgression. Answering this question requires

275 employment of nuclear marker, what leaves a space for the future studies - much wider in terms

276 of geographic coverage and molecular markers used.

277 Concluding, we have demonstrated that Pleistocene glaciations and associated sea level changes

278 in the Mediterranean/Pontic region had a profound effect on the genetic diversity and distribution

279 of widely distributed coastal insect species, generating some level of cryptic diversity. Our case

280 study casts more light on the evolutionary relationships between populations of terrestrial animals

281 inhabiting both the Mediterranean and Black Sea shorelines - a phenomenon that is still weakly 282 explored in literature.

283

284 Acknowledgements

285 The first author would like to thank to Iwona Jaroszewska, Piotr Jóźwiak, Błażej Pawicki, Maciej

286 Podsiadło, Anna Stepień, and Bartosz Ukleja for their kind help during and material collecting 287 TB-Quest Expedition to the Balkans.

289 Literature

290 Altschul SF, Gish W, Miller W, Myers EW, Lipman DJ. 1990. Basic Local Alignment Search

291 Tool. Journal of Molecular Biology 215: 403-410. 
292 Akin C, Bilgin CC, Beerli P, Westaway R, Ohst T, Litvinchuk SN, Uzzell T, Bilgin M, Hotz H,

293 Guex GD, Plötner J. 2010. Phylogeographic patterns of genetic diversity in eastern

294 Mediterranean water frogs were determined by geological processes and climate change in the

295 Late Cenozoic. Journal of Biogeography 37 (11): 2111-2124.

296 Audzijonyte A, Daneliya ME, Vainola R. 2006. Comparative phylogeography of Ponto-Caspian

297 mysid crustacean: isolation and exchange among dynamic inland sea basins. Molecular Ecology

298 15: 2969-2984.

299 Avgin S, Özdikmen H. 2007. Check-list of tiger beetles of Turkey with review of distribution

300 and biogeography (Coleoptera: Cicindelidae). Munis Entomology and Zoology 2 (1): 87-102.

301 Avise JC. 1992. Molecular population structure and the biogeographic history of a regional

302 fauna: a case history with lessons for conservation biology. Oikos 63: 62-76.

303 Badertscher S, Fleitmann D, Cheng H, Edwards RL, Göktürk OM., Zumbühl A, Leuenberger M,

304 Tüysüz O. 2011. Pleistocene water intrusions from the Mediterranean and Caspian seas into the 305 Black Sea. Nature Geoscience 4: 236- 239.

306 Blondel J, Aronson J, Bodiou J-Y, Boeuf G. 2010. The Mediterranean Region. Biological

307 Diversity in Space and Time. $2^{\text {nd }}$ Edition. Oxford: Oxford University Press.

308 Böhme MU, Fritz U, Kotenko T, Džukić G, Ljubisavljević K, Tzankov N, Berendonk TU. 2007.

309 Phylogeography and cryptic variation within the Lacerta viridis complex (Lacertidae, Reptilia).

310 Zoologica Scripta 36: 119-131.

311 Brower AVZ. 1994. Rapid morphological radiation and convergence among races of the

312 butterfly Heliconius erato inferred from patterns of mitochondrial DNA Evolution. Proceedings

313 of the National Academy of Sciences USA 91: 6491-6495. 
314 Caković D, Stešević D, Schönswetter P, Frajman B. 2015. How many taxa? Spatiotemporal

315 evolution and taxonomy of Amphoricarpos (Asteraceae, Carduoideae) on the Balkan Peninsula.

316 Organisms Diversity \& Evolution 15(3): 429-445.

317 Cardoso A, Vogler AP. 2005. DNA taxonomy, phylogeny and Pleistocene diversification of the

318 Cicindela hybrida species group (Coleoptera: Cicindelidae). Molecular Ecology 14: 3531-3546.

319 Cardoso A, Serrano A, Vogler AP. 2009. Morphological and molecular variation in tiger beetles

320 of the Cicindela hybrida complex: is an 'integrative' taxonomy possible? Molecular Ecology 18:

$321 \quad 648-664$.

322 Cassola F, Jaskuła R. 2004. Material to the knowledge of the tiger beetles of Romania

323 (Coleoptera: Cicindelidae). Polskie Pismo Entomologiczne 73: 193-214.

324 Chenna R, Sugawara H, Koike T, Lopez R, Gibson TJ, Higgins DG, Thompson JD. 2003.

325 Multiple sequence alignment with the Clustal series of programs. Nucleic Acids Research 31:

$326 \quad 3497-3500$.

327 Clarke KR, Gorley RN. 2006. PRIMER v6: User Manual/Tutorial. PRIMER-E, Plymouth.

328 Drummond AJ, Rambaut A, Shapiro B, Pybus OG. 2005. Bayesian coalescent inference of past 329 population dynamics from molecular sequences. Molecular Biology and Evolution 22: $1185-$ 3301192.

331 Drummond AJ, Suchard MA, Xie D, Rambaut A. 2012. Bayesian Phylogenetics with BEAUti 332 and the BEAST 1.7. Molecular Biology and Evolution 29: 1969-1973.

333 Dutton A, Lambeck K. 2012. Ice volume and sea level during the last interglacial. Science 337 334 (6091): 216-219. 
335 Excoffier L, Lischer HEL. 2010. Arlequin suite ver 3.5: a new series of programs to perform

336 population genetics analyses under Linux and Windows. Molecular Ecology Resources 10: 564-

337567.

338 Fagan B (ed.). 2009. The complete Ice Age. How climate change shaped the world. London:

339 Thames \& Hudson Ltd.

340 Ferchaud A-L, Ursenbacher S, Cheylan M, Luiselli L, Jelić D, Halpern B, Major A, Kotenko T,

341 Keyan N, Behrooz R, Crnobrnja-Isailović J, Tomović L, Ghira I, Ioannidis Y, Arnal V,

342 Montgelard C. 2012. Phylogeography of the Vipera ursinii complex (Viperidae): mitochondrial

343 markers reveal an east-west disjunction in the Palaearctic region. Journal of Biogeography 39:

$344 \quad 1836-1847$.

345 Franzen M. 2006. Verbreitung und Lebensräume der Sandlaufkäfer der Peloponnes-Halbinsel,

346 Griechenland (Coleoptera, Cicindelidae). Nachrichtenblatt der Byerischen Entomologen 55

347 (3/4): 46-64.

348 Grinevetsky SR, Zonn IS, Zhiltsov SS, Kosarev AN, Kostianoy AG. 2015. The Black Sea

349 Encyclopedia. Berlin: Springer.

350 Hebert PDN, Cywinska A, Ball SL, deWaard JR. 2003a. Biological identification through DNA

351 barcodes. to the fast publication and worldwide dissemination of high-quality research.

352 Proceedings of the Royal Society of London B: Biological Sciences 270: 313-321.

353 Hebert PDN, Ratnasingham S, deWaard JR. 2003b. Barcoding animal life: cytochrome c oxidase

354 subunit 1 divergences among closely related species. Proceedings of the Royal Society of London

355 B: Biological Sciences Suppl. 27: 96-99.

356 Hillis DM, Moritz C, Mable BK. 1996. Molecular Systematics, $2^{\text {nd }}$ ed. Sunderland: Sinauer 357 Associates. 
358 Huemer P., Timossi G. 2014. Sattleria revisited: unexpected cryptic diversity on the Balkan

359 Peninsula and in the south-eastern Alps (Lepidoptera: Gelechiidae). Zootaxa 3780 (2): 282-296.

360 Huson DH, Bryant D. 2006. Application of Phylogenetic Networks in Evolutionary Studies,

361 Molecular Biology and Evolution 23(2): 254-267.

362 Jaskuła R. 2007a. Remarks on distribution and diversity of the tiger beetle fauna (Coleoptera:

363 Cicindelidae) of Albania. Fragmenta Faunistica 50 (2): 127-138.

364 Jaskuła R. 2007b. Furthern records of tiger beetles from Romania (Coleoptera: Cicindelidae).

365 Cicindela 39 (1-2): 27-34.

366 Jaskuła R. 2011. How unique is the tiger beetle fauna (Coleoptera, Cicindelidae) of the Balkan

367 Peninsula? ZooKeys 100: 487-502.

368 Jaskuła R. 2013. Unexpected vegetarian feeding behaviour of a predatory tiger beetle Calomera

369 littoralis nemoralis (Olivier, 1790) (Coleoptera: Cicindelidae). Journal of the Entomologcal

370 Research Society 15(1): 01-06.

371 Jaskuła R. 2015. The Maghreb - one more important biodiversity hot spot for tiger beetle fauna

372 (Coleoptera, Carabidae, Cicindelinae) in the Mediterranean region. ZooKeys 482: 35-53.

373 Jaskuła R, Peśić V, Pavicević D. 2005. Remarks on distribution and diversity of the tiger beetle

374 fauna of Montenegro (Coleoptera: Cicindelidae). Fragmenta Funistica 4 (1): 15-25.

375 Kerey IE, Meric E, Tunoglu C, Kelling G, Brenner RL, Dogan AU. 2004. Black Sea-Marmara

376 Sea Quaternary connections: new data from the Bosphorus, Istanbul, Turkey. Palaeogeography,

377 Palaeoclimatology, Palaeoecology 204: 277-295.

378 Kopp RE, Simons FJ, Mitrovica JX, Maloof AC, Oppenheimer M. 2009. Probabilistic

379 assessment of sea level during the last interglacial stage. Nature 462 (7275): 863-867. 
380 Kotlík P, Bogutskaya NG Ekmekçi FG. 2004. Circum Black Sea phylogeography of Barbus

381 freshwater fishes: divergence in the Pontic glacial refugium. Molecular Ecology 13: 87-95.

382 Kryštufek B, Reed M. 2004 Patterns and Process in Balkan Biodiversity - an overview. In:

383 Griffiths HI, Kryštufek B, Reed JM. (Eds) Balkan Biodiversity: Pattern and Process in the

384 European Hotspot. Dordrecht, Kluwer Academic Publishers, 203-217.

385 Librado P, Rozas J. 2009. Dna SPv5: a software for comprehensive analysis of DNA

386 polymorphism data. Bioinformatics 25: 1451-1452.

387 Lisiecki LE., Raymo ME. 2005. A Pliocene-Pleistocene stack of 57 globally distributed benthic

$388 \delta^{18} \mathrm{O}$ records. Paleoceanography 20 (10): 1-17.

389 López-López A, Abdul Aziz A, Galián J. 2015.Molecular phylogeny and divergence time

390 estimation of Cosmodela (Coleoptera: Carabidae: Cicindelinae) tiger beetle species from

391 Southeast Asia. Zoologica Scripta 44: 437-445.

392 López-López A, Hudson P, Galián J. 2012. The blackburni/murchisona species complex in

393 Australian Pseudotetracha (Coleoptera: Carabidae: Cicindelinae: Megacephalini): evaluating

394 molecular and karyological evidence. Journal of Zoological Systematics and Evolutionary

395 Research 50 (3): 177-183.

396 Mandl K. 1981. Revision der unter Cicindela lunulata F. im Weltkatalog der Cicindelinae

397 zusammengefaßten Formen (Col., Cicindelidae). Entomologische Arbeiten aus dem Museum Gg.

398 Frey 29: 117-176.

399 Marks L. 2011. Quaternary glaciations in Poland. [in:]: EhlersJ., GibbardP.L., Hughes P.D.

400 (eds.) Quaternary Glaciations - Extent and Chronology, a closer look. Developments in

401 Quaternary Science 15: 299-303. 
402 Myers N, Mittermeier RA, Mittermeier CG, da Fonseca GAB, Jennifer K. 2000. Biodiversity 403 hotspots for conservation priorities. Nature 403: 853-858.

404 Nahavandi N, Ketmaier V, Plath M, Tiedemann R. 2013. Diversification of Ponto-Caspian 405 aquatic fauna: Morphology and molecules retrieve congruent evolutionary relationships in 406 Pontogammarus maeoticus (Amphipoda: Pontogammaridae). Molecular Phylogenetics and 407 Evolution 69: 1063-1076.

408 Neilson ME, Stepien CA. 2011. Historic speciation and recent colonization of Eurasian monkey 409 gobies (Neogobius fluviatilis and N. pallasi) revealed by DNA sequences, microsatellites, and 410 morphology. Diversity and Distributions 17: 688-702.

411 Pearson DL, Cassola F. 2005. A quantitative analysis of species descriptions of tiger beetles 412 (Coleoptera: Cicindelidae), from 1758 to 2004, and notes about related developments in 413 biodiversity studies. The Coleopterologist Bulletin 59 (2): 184-193.

414 Pearson DL, Vogler AP. 2001. Tiger beetles: the evolution, ecology, and diversity of the 415 cicindelids. Ithaca and London: Cornell University Press.

416 Pfiffner OA. 2014. Geology of the Alps. New York: Wiley Blackwell.

417 Previšić A, Wolfram G, Vitecek S, Waringer J. 2014. Cryptic diversity of caddisflies in the 418 Balkans: The curious case of Ecclisopteryx species (Trichoptera: Limnephilidae). Arthropod 419 Systematics and Phylogeny 72(3): 309-329.

420 Puillandre N, Lambert A, Brouillet S, Achaz G. 2012. ABGD, Automatic Barcode Gap 421 Discovery for primary species delimitation. Molecular Ecology 21(8): 1864-77.

422 Putchkov AV, Matalin AV. 2003. Subfamily Cicindelinae Latreille, 1802. In: Löbl L, Smetana 423 A. (Eds) Catalogue of Palaearctic Coleoptera. V.1. Archeostemata-Myxophaga-Adephaga. 424 Strenstrup: Apollo Books, 99-118. 
425 Rogers AR., Harpending H. 1992. Population growth makes waves in the distribution of pairwise 426 genetic differences. Molecular Biology and Evolution 9: 552-569.

427 Serrano J. 2013. New catalogue of the family Carabidae of the Iberian Peninsula (Coleoptera).

428 Madrid: Editum - Ediciones de la Universidad de Murcia.

429 Simon C, Frati F, Beckenbach AT, Crespi B, Liu H, Flook P. 1994. Evolution, weighting, and

430 phylogenetic utility of mitochondrial gene sequences and a compilation of conserved polymerase

431 chain reaction primers. Annals of Entomological Society of America 87: 51-701.

432 Slatkin M, Hudson RR. 1991. Pairwise comparisons of mitochondrial DNA sequences in stable 433 and exponentially growing populations. Genetics 129: 555-562.

434 Sota T, Liang H, Enokido Y, Hori M. 2011. Phylogeny and divergence time of island tiger

435 beetles of the genus Cylindera (Coleoptera: Cicindelidae) in East Asia. Biological Journal of the 436 Linnean Society 102: 715-727.

437 Stanley DJ, Blanpied C. 1980. Late Quaternary water exchange between the eastern

438 Mediterranean and the Black Sea. Nature 285 (5766): 537-541.

439 Tajima F. 1989. Statistical method for testing the neutral mutation hypothesis by DNA

440 polymorphism. Genetics 123: 585-595.

441 Tamura K, Stecher G, Peterson D, Filipski A, Kumar S. 2013. MEGA6: Molecular Evolutionary

442 Genetics Analysis version 6.0. Molecular Biology and Evolution 30: 2725-2729.

443 Tsuji K, Hori M, Phyu MH, Liang H, Sota T. 2016. Colorful patterns indicate common ancestry

444 in diverged tiger beetle taxa: molecular phylogeny, biogeography, and evolution of elytral

445 coloration of the genus Cicindela subgenus Sophiodela and its allies. Molecular Phylogenetics 446 and Evolution 95: 1-10. 
447 Vogler AF, DeSalle R. 1993. Phyllogeographic patterns in coastal North American tiger beetles

448 (Cicindela dorsalis Say) inferred from mitochondrial DNA sequences. Evolution 47 (4): 1192-

4491202.

450 Vogler AP, Pearson DL. 1996. A molecular phylogeny of the tiger beetles (Cicindelidae):

451 congruence of mitochondrial and nuclear rDNA data sets. Molecular Phylogenetics and

452 Evolution $6(3): 321-338$.

453 Vogler AP, Knisley CB, Glueck SB, Hill JM, DeSalle R. 1993. Using molecular and ecological

454 data to diagnose endangered populations of the puritan tiger beetle Cicindela puritana.

455 Molecular Ecology 2: 375-383.

456 Werner K. 1991. Cicindelidae Regionis Palaearcticae. Megacephalini: Megacephala,

457 Cicindelini 1: Cicindela-Lophyridia. The Beetles of the World 13. Compiègne: Sciences Nat..

458 Woodcock MR, Kippenhan MG, Knisley CB, Foster JA. 2007. Molecular genetics of Cicindela

459 (Cylindera) terricola and elevation of Cicindela lunalonga to species level, with comments on its

460 conservation status. Conservation Genetics 8: 865-877.

461 


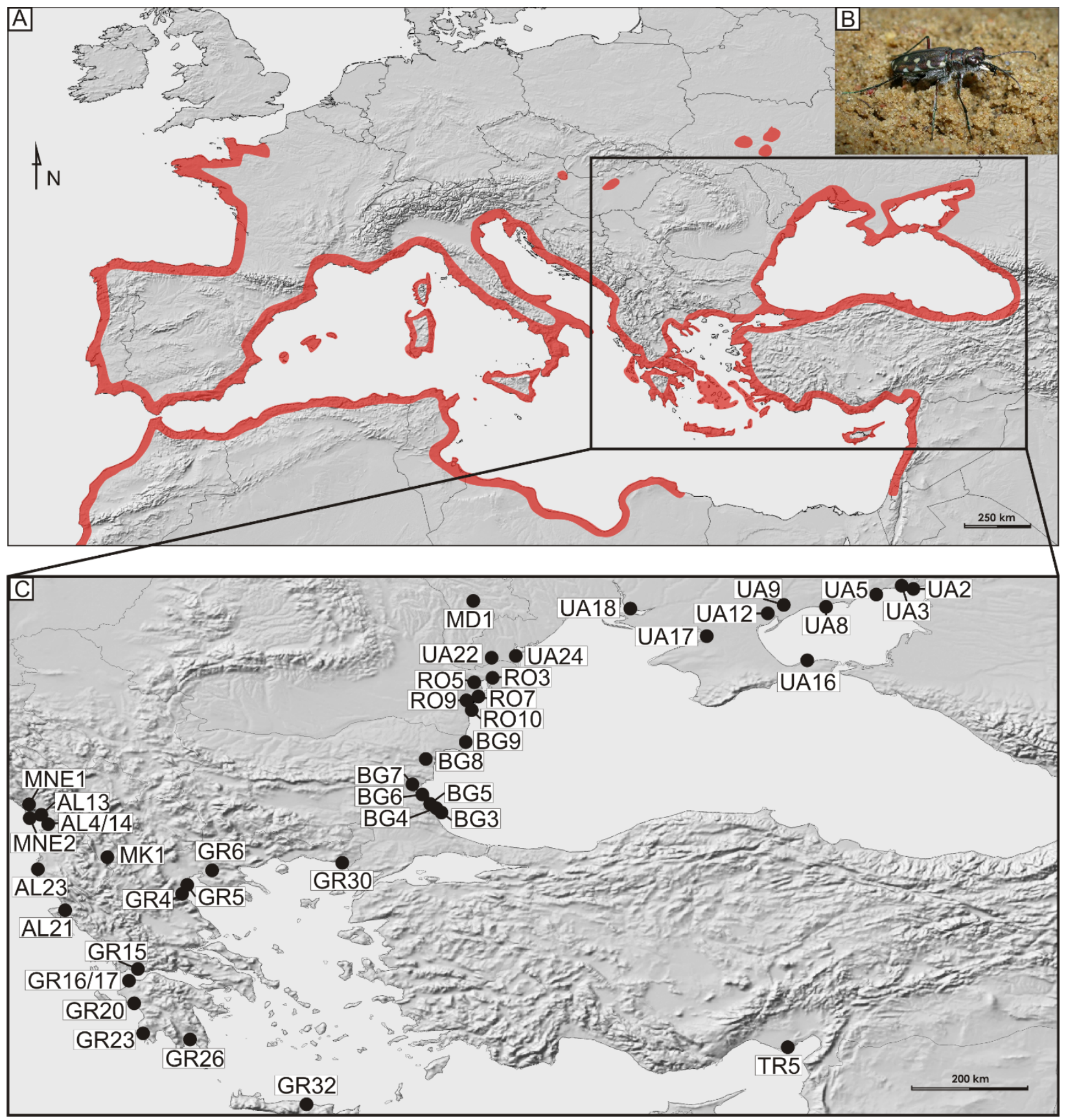

463 Figure 1. Distribution and sampling of Calomera littoralis in Europe. (A) General distribution of

464 Calomera littoralis in Europe shown as red-shaded area. (B) Picture of Calomera littoralis beetle.

465 (C) Sampling sites in Balkan Peninsula, Black Sea region and Turkey shown as black dots.

466 Localities coded as in Table 1. 


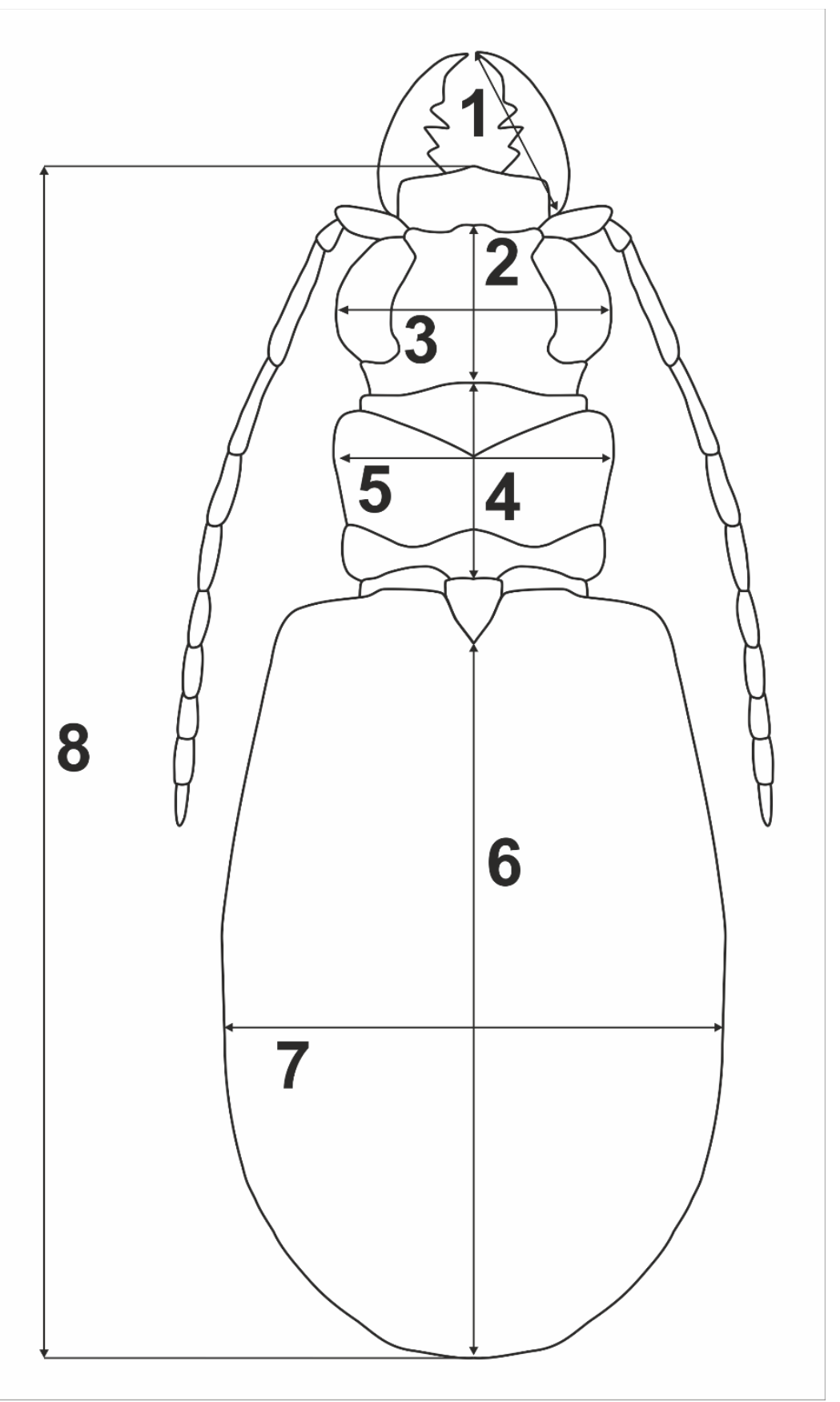

469 Figure 2. Body parameters measured in Calomera littoralis. 1 - RLM - right mandible length, 2 $470-\mathrm{WH}-$ length of head, 3 - LH -width of head, 4 - PL - pronotum length, 5 - MPW - maximum 471 pronotum width, 6 - EL - elytra length, 7 - MEW - maximum elytra width, 8 - TBL - total body 472 length. 
A
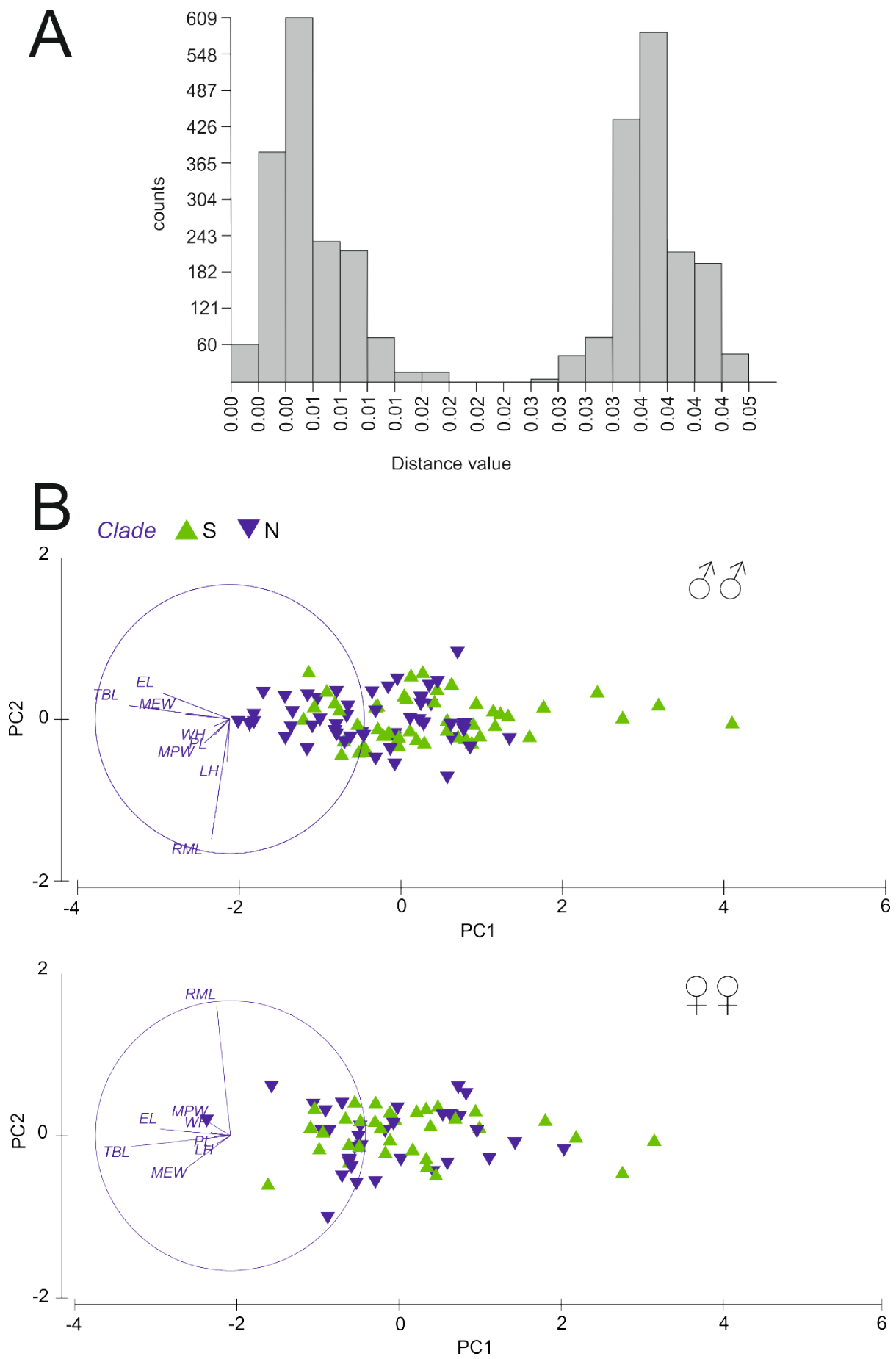

$\mathrm{PC} 1$

475 Figure 3. (A) Automatic Barcode Gap Discovery (ABGD) analysis of Calomera littoralis and (B) 476 Results of Principal Component Analysis performed for investigated specimens on main body 477 dimensions. S - southern lineage, $\mathrm{N}$ - northern lineage, RLM - right mandible length, WH - width 478 of head, LH - length of head, MPW - maximum pronotum width, PL - pronotum length, EL - 
479 elytra length, MEW - maximum elytra width, TBL - total body length. Both in ABGD and PCA 480 analyses 169 specimens from 43 sites from the Mediterranean and the Pontic areas were used. 


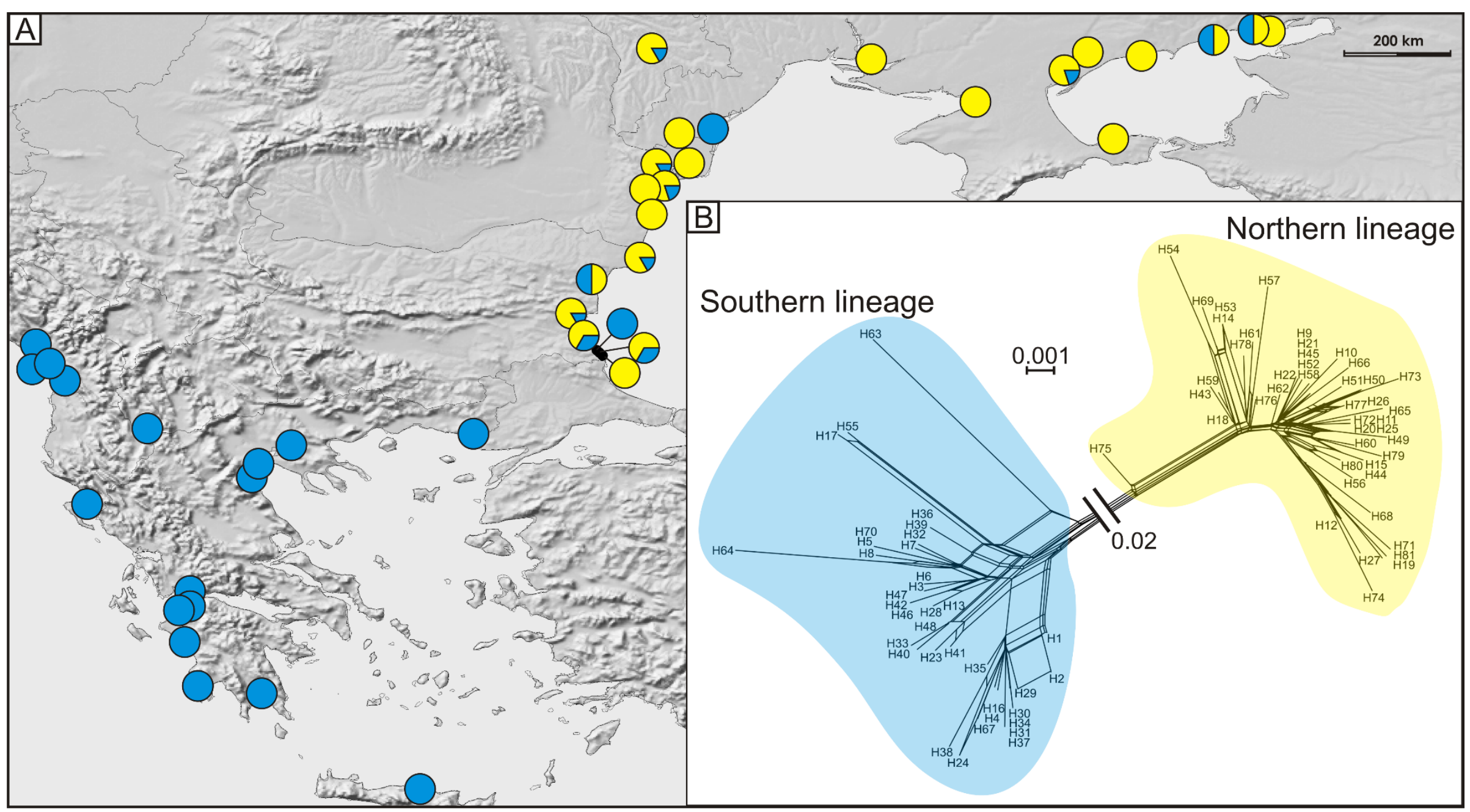

Figure 4. (A) Geographic distribution of haplogroups from southern (blue circles) and northern (yellow circles) lineages (B). 

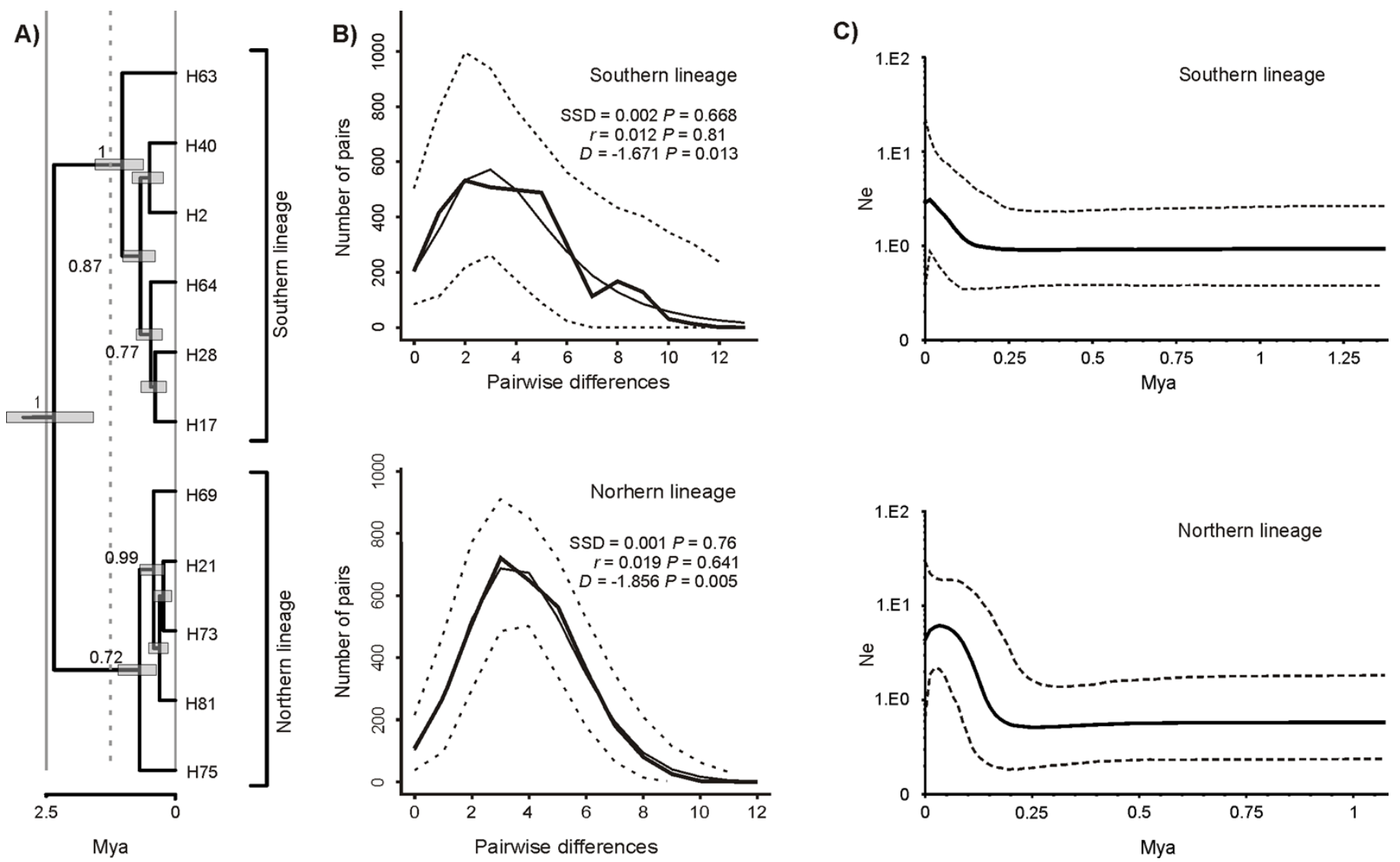

485 Figure 5. Phylogeny and historical demography of Calomera littoralis. (A) Maximum clade credibility chronogram with a strict molecular clock model inferred from COI sequences. The numbers next to the respective node indicate Bayesian posterior probabilities

487 higher than 0.5. (B) Mismatch plots for southern and northern lineage. Thin solid lines indicate expected frequency under model of population demographic expansion, thick solid lines represent observed frequency, and dashed lines indicate $95 \%$ confidence intervals 
490 plots for southern and northern lineages of Calomera littoralis. Solid lines indicate the median posterior effective population size through

491 time; dashed lines indicate the $95 \%$ highest posterior density interval for each estimate. 